\title{
Espaço, tempo e religião: devoção da Medalha Milagrosa em París, França
}

\author{
Space, time and religion: devotion of the \\ Miraculous Medal in Paris, France
}

Zeny Rosendah/*

Resumo: Deseja-se sugerir uma maneira particular de olhar as cidades em relaçáo ao seu contexto cultural, estabelecendo um elo entre espaço, tempo e religião. A interpretação do sagrado como elemento do espaço, a análise do tempo em que ocorreu, a hierofania no lugar, são os caminhos metodológicos valorizados no texto. Paris - a cidade-santuário - sustenta a permanência do espaço sagrado da Capela da Rue du Bac, ambas são exemplos de lugar de memória cujas manifestação de fé religiosa compóe o tema central deste artigo. O roteiro devocional dos visitantes e o alcance espacial dos devotos ao Santuário da Medalha Milagrosa completam a pesquisa realizada, tanto na parte teórica como na análise empírica.

Palavras-chave: Medalha Milagrosa. Capela da Rue du Bac. Cidade-santuário. Espaço sagrado. Memória.

Abstract: We want to suggest a particular way of looking at cities in relation to their cultural context, establishing a link between space, time and religion. The interpretation of the sacred as an element of space, the analysis of the time in which it occurred, the hierophany in place, are the methodological paths valued in the text. Paris - the sanctuary city - maintains the permanence of the sacred space of the Chapel of the Rue du Bac, both are examples of place of memory whose manifestation of religious faith composes the central theme of this article. The devotional itinerary of the visitors and the spatial reach of the devotees to the Shrine of the Miraculous Medal complete the research carried out, both in the theoretical part and in the empirical analysis.

Keywords: Miraculous Medal. Chapel of the Rue du Bac. Holy city. Sacred space. Memory.

\section{Introduçáo}

Este artigo tem a preocupação de apresentar o estudo da religião pelo olhar geográfico. A religião constitui um fato social e como tal exige uma necessária temporalidade e espacialidade, isto é, estar inscrita no tempo e no espaço. Na ciência geográfica a espacialidade adquiri ênfase importante. A geografia e a religião se encontram através da dimensáo espacial, uma porque analisa o espaço, a outra porque, como fenômeno cultural, ocorre espacialmente (Rosendahl, 2003). A ideia de sagrado, na visão geográfica está em comunhão com as reflexóes dos estudiosos da religiáo: quer como poder de coesão durkheimiano; como a força carismática do weber; na manifestação hierofânica de Mircea Eliade; e na qualidade de numinoso de Otto.

* Professora Pesquisadora Visitante do PPG em Geografia da UERJ. Fundadora do NEPEC. ORCID: 0000-0001-7206-9435 - contato: zeny.rosendahl@gmail.com 
As investigações da dimensão espacial do sagrado devem ser interpretadas como o estudo da ação desempenhada pela motivação religiosa do homem em sua criação do espaço sagrado bem como, as sucessivas transformaçóes espaços-temporais. Supóe-se a existência de um impulso religioso no homem que o leva a agir sobre o seu ambiente, qualificando-o com formas espaciais religiosas que estão diretamente relacionadas com seus desejos. São marcas simbólicas que respondem as necessidades do devoto em suas práticas e atividades espaciais religiosas conforme apontam os estudos de Isaac (1959, 1960); Sack (1986); Sopher (1981); Allison (1989); Kong (1990, 1999, 2001); Rosendahl (2009, 2012, 2018) entre outros pesquisadores.

As categorias de analise como imagem e simbolismo; valor e, significado; identidade e pertencimento completam as ideias os conceitos geográficos de espaço, lugar, território e paisagem. O ver e sentir o sagrado é privilegiado nos estudos em geografia da religião.

O caminhar teórico-metodológico da investigação na relação entre religião e geografia verifica-se em múltiplas escalas geográficas, e em cada uma a interpretação caracteriza-se por estratégias e poder e forma espacial de sua organização. Na escala do lugar, a construção do espaço sagrado nas cidades-santuários ou hierópolis (Rosendahl, 2009), bem como a demarcação dos itinerários simbólicos vêm nos fortalecendo a necessidade contínua de tais estudos geográficos. Neste artigo consideramos cidade-santuário ou hierópolis, os centros de convergência de peregrinos com suas práticas e crenças que materializam uma peculiar organização funcional e social de/no espaço. Tal arranjo espacial singular e repetitivo pode ser de natureza permanente ou apresentar uma periodicidade marcada por tempos de festividades próprias de cada centro de peregrinação.

A pesquisa de campo deve ser incentivada como instrumento metodológico, pois permite ao pesquisador privilegiar a etnogeografia (Claval e Singaravelou, 1995), lembrando sempre que o lugar pesquisado favorece ao exercício da fé e da identidade religiosa do devoto em suas práticas espaciais religiosas.

Há na geografia brasileira, estudos realizados no NEPEC - Núcleo de Estudos e Pesquisas sobre Espaço e Cultura, que priorizaram a interpretação das seguintes hierópolis: Santuário do Cristo em Porto das Caixas, Itaboraí (RJ); Santuário de Santa Cruz dos Milagres (PI); Nossa Senhora de Caravaggio (R. G do Sul); São Benedito - Jaraguá (GO); São Francisco do Canindé (CE); Santuário de Quixadá (CE), Festa do Círio de Nazaré em Belém (PA); Santuário do Pai das Misericórdias - Cachoeira Paulista (SP); Santuário de Nossa Senhora Aparecida - Aparecida (SP); acrescenta-se os internacionais como: Santuário de Chartres (França); A Catedral de Cristo Salvador em Moscou (Rússia); Santuário de Czestochowa, Mosteiro de Jasna Góra (Polônia). Acrescenta-se, neste artigo, o estudo da devoção religiosa popular com semelhanças e diferenças espaciais da religiosidade católica no lugar: Hierópolis da Medalha Milagrosa - Paris, França.

\section{Le message de Marie à Sainte Catherine Labouré}

A noviça Catherine Labouré ingressou na Congregação das Filhas da Caridade de Sáo Vicente de Paulo, na França, em abril de 1830. As mensagens religiosas relatadas pela noviça estão relacionadas com as aparições da Virgem Maria, na capela da Congregação 
Religiosa, número 140, na Rue du Bac, Paris. A difusão da fé e de amor na mensagem está contida na frase: $O$ Maria concebida sem pecado, rogai por nós, que recorremos a Vós!

A temporalidade da devoçáo inicia-se no dia 27 de novembro de 1830. A espacialidade marcada nas visitas da Virgem Maria à noviça permanece ainda hoje. Na Capela da Rue du Bac - como o lugar é conhecido entre os visitantes, os turistas religiosos e os peregrinos devotos em peregrinação na capital francesa. A abordagem da organização espacial no espaço e no tempo sagrado serão refletidas e ratificadas neste artigo.

A capela da Rue du Bac é um exemplo de lugares de memória, expressão criada por Pierre Nora ao interpretar formas simbólicas espaciais religiosas que têm em suas manifestaçôes materiais de fé, ritos impregnados de significados em torno do passado. Neles a memória está cristalizada e transpira, gerando o "sentido da continuidade histórica" (Nora, 1989, p. 7). A capela da Rue du Bac possui vibraçáo da fé católica distinta de outros lugares. $\mathrm{O}$ espírito do lugar religioso permanece material, a imaginação religiosa da comunidade religiosa imprime forte significado no lugar. A devoçáo religiosa na história dos homens está impregnada de símbolos e significados. O catolicismo possui ritos que expressam suas crenças.

A aparição da Virgem Maria à Catherine Labouré permitiu a criação do objeto de difusão da mensagem religiosa, nas falas da devota formou-se, entáo, em torno de Nossa Senhora um quadro oval, onde havia no alto estas palavras escritas: Ó Maria Concebida sem pecado, rogai por nós, que recorremos a Vós (Martins, 2004). O símbolo da devoção não é a imagem da pessoa que recebeu a mensagem - a noviça Labouré -, nem a imagem da visita da Virgem à noviça. O símbolo é a medalha em forma oval sugerido pela Virgem à Labouré - a mensagem dada foi cunhar a medalha que traria graças a quem a usasse com efetiva confiança na mãe de Deus.

A medalha é um símbolo religioso na propaganda da devoção aos santos. Na difusão da fé e veneração da devoção mariana também. Inicialmente a devoção foi na medalha chamada Medalha da Imaculada Conceição. De forma oval com a imagem da Virgem Maria e no verso a letra $M$ encimada por uma cruz, o qual tinha uma barra em sua base. Embaixo, figuram o Coração de Jesus, coroado de espinhos e o Coraçáo de Maria atravessado por uma espada. A relação santíssima de mãe e filho são mostradas. Contornando a medalha são doze estrelas. A medalha possui a identidade religiosa da Virgem Maria (Figura 1).

\section{Figura 1 - A medalha milagrosa.}

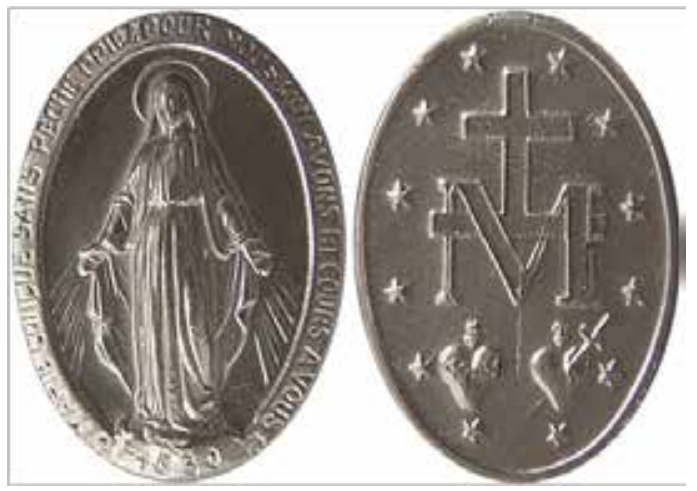

Fonte: Rosendahl (2017). 


\section{$140 \mid$ Zeny Rosendahl}

\section{Cultura e memória: a Capela da Medalha Milagrosa}

A medalha da Imaculada Conceição foi distribuída em março de 1832 nos hospitais e na Capela da Congregação. Paris vivia um contexto de doenças - cólera principalmente -, e a distribuição entre a populaçáo refletiu resultados positivos sobre a epidemia. Incríveis resultados de cura, proteção e graças na saúde foram atribuídos ao poder da medalha. Tais curas em doentes e outros pedidos favoreceram rapidamente a devoção entre os devotos. A procura pela medalha aumenta e se populariza. A cura de doentes que tinham a medalha no pescoço era visivelmente superior aos outros que não a tinham (Santos, 1998).

Um novo nome surgiu entre a populaçáo devota - A Medalha Milagrosa - em 1894, a festa litúrgica da Chapelle Notre-Dame de la Médaille Miraculeuse, como é conhecida hoje, entre os peregrinos que se dirigem à capela (Fille de La Charité, s/data). Os dias festivos com celebraçóes são: 27 de novembro, 8 de dezembro e 31 de dezembro.

Nestes tempos sagrados a Capela da Medalha Milagrosa recebe a visita de devotos franceses em maior número. A peregrinação a Paris ocorre em tempo contínuo. O tempo de festa tem sua comemoração na capela com forte frequência de moradores da capital francesa. As peregrinações durante todo o ano são organizadas pela Administração do Convento das Filhas da Caridade de São Vicente de Paulo. Atendem vários países católicos europeus e as peregrinaçóes acontecem com data e hora previamente marcadas. A administração religiosa recebe os peregrinos com apoio linguístico e com as atividades religiosas antecipadamente marcadas. As práticas religiosas individuais são livres. As relações espaço/lugar e tempo são elaboradas com antecedência.

O lugar de peregrinação é um local pequeno. A Rue du Bac, rua de comércio, estreita, sem local para estacionamento próximo ao convento. A porta principal de acesso ao convento e ao lugar sagrado da capela não permite de imediato reconhecer na paisagem a existência de uma capela, ou mesmo de catedral, tấo comum na Europa católica. Os geógrafos sinalizam desde a primeira metade do século XX locais que podem ser interpretados de como as pessoas e o grupo religioso imprimem seus valores e crenças em formas espaciais religiosas (Claval, 2008). Os geógrafos invocam as marcas que a religião imprime diretamente na paisagem, na capela, nos lugares de culto; a repetição dos mesmos símbolos, ao longo do tempo amplia os lugares de culto.

A Capela da Medalha Milagrosa é uma marca relativamente discreta, familiar em sua repetição cotidiana no lugar. É necessário que o peregrino ou visitante tenha o conhecimento da existência e da história do lugar. Em Paris, o simbolismo religioso do lugar sagrado da Rue du Bac, os peregrinos convergem impregnados na devoção à Medalha Milagrosa. Há no lugar identidades de peregrinos, visitantes e turistas religiosos, em uma relação recíproca com a identidade do grupo religioso que frequenta a capela.

O sagrado irrompe em determinados lugares como revelaçôes hierofânicas, transformando-os qualitativamente em poderosos "centros do mundo significativos, separados do espaço comum, do cotidiano profano" (Eliade, 1991). O lugar é ritualmente construído. A criação de lugares é um ato social; os lugares diferem porque as pessoas os fizeram assim (Norton, 2000); por meio de uma variedade de emoçóes, como o "numinoso que atinge a profundeza da alma" (Otto, 1992); revela-se como um dom 
carismático que o objeto ou a pessoa possui (Weber, 1964); se impóe por ele mesmo (Durkheim, 1968; Berger, 1985); ou como "alquimia ideológica pela qual se opera a transfiguração das relaçóes sociais em relaçóes sobrenaturais, inscritas na natureza das coisas, e, portanto, justificadas" (Bourdieu, 1987, p. 33).

O processo de construção do lugar sagrado envolve esforço e cooperação da comunidade religiosa. É marcante a relação dialética entre a política da comunidade e a construçáo do lugar sagrado na Capela da Rue du Bac. A comunidade religiosa constrói o lugar sagrado de devoção da Medalha Milagrosa e está, na função religiosa de comunhão social, sustenta a própria comunidade (Rosendahl, 2003b).

\section{O sagrado e o urbano na Rue du Bac: turismo religioso e peregrinaçóes}

A interpretação e cidade-santuário católica em área urbana pode ser ressaltada, no olhar geográfico, a partir de três categorias geográficas fundamentais: (i) forma especial; (ii) função devocional e; (iii) as interações espaciais. Iremos, também, privilegiar o turismo religioso e a convergência de peregrinos que norteiam o espaço sagrado de forte devoção popular. A escolha...

i. A forma simbólica espacial religiosa impressa na paisagem urbana de Paris vem fornecendo, indicadores espaço-tempo de continuidade nestes 20 anos de existência. A pesquisa empírica ocorreu inicialmente nos anos de 1997/1998. O mural dos ex-votos no corredor de entrada da Capela da Medalha Milagrosa, o horário de funcionamento de visita e o atendimento em diferentes idiomas aos romeiros, retratam a temporalização do sagrado no lugar.

ii. A função simbólica espacial religiosa de devoção possui um papel singular em comparação com outras hierópolis católicas localizadas em áreas urbanas. A literatura assinala que forma e função andam juntas e podem variar de tamanho, de estilo, de arquitetura, material de construção e grau de ornamento. A Capela da Medalha Milagrosa em sua funçáo devocional permanece evidenciando a forma espacial da capela, dentro de uma Instituição Religiosa e não em um estilo catedral. $\mathrm{O}$ arranjo espacial religioso permanece com seus olhares, suas imagens e o seu roteiro devocional. A função das hierópolis é abrigar o sagrado, e será eficiente na medida em que represente aos devotos a experiência da religiáo, porque somente ali, na singularidade do espaço sagrado, o fiel pode conectar sua atenção, e exprimir sob formas simbólicas religiosas seu relacionamento pessoal com a divindade (Rosendahl, 1997, 2013, 2018).

iii. A Capela da Medalha Milagrosa confere a Paris a função de cidade de peregrinação. Em pesquisa realizada na Capela, nos registros dos visitantes de 1995 a 1997, no setor Administrativo de Registros de Peregrinos é possível afirmar que os peregrinos que chegaram à Capela da Medalha Milagrosa vinham de países de fonte religiosa católica como Polônia, Itália, Alemanha, Bélgica, Áustria, Portugal, Filipinas, Argentina e Brasil. O fluxo proveniente de peregrinos de países de minorias católicas foi documentado, a saber: Indonésia, Austrália e China. A pesquisa empírica relata a presença de trinta e quatro países numa intensidade permanente com padróes espaciais locais e internacionais. 
Em visita à Capela no ano de 2015 pude constatar a atualidade da pesquisa anterior feita no gabinete do Setor Administrativo. Ocorre que nesta segunda ocorrência a leitura dos dados à funcionária, foram considerados como atuais. A pesquisa estatística náo ocorreu, mas a análise qualitativa foi realizada com os visitantes estrangeiros que em grupos organizados agendam sua visita no espaço-tempo de sua convivência. Sendo assim, acrescentam-se as interpretaçóes das interaçóes espaciais religiosas.

O alcance espacial dos peregrinos que visitaram o santuário da Medalha Milagrosa, referenciados na pesquisa acima, pode ser visualizado pela Figura 2, para a variabilidade espaço-temporal das interaçóes.

A pesquisa possibilitou analisar o padrão de interação de peregrinação religiosa ao descrever interaçôes fortemente internacionais, que se fazem a longa distância, envolvendo múltiplos fluxos de peregrinos, de visitantes e de turistas. Os centros de peregrinação do catolicismo de maneira geral atraem fiéis de países católicos e devotos católicos de países não católicos.

As interaçôes espaciais religiosas são influenciadas pela atuação dos participantes e realçadas pela mídia: quanto menos conhecimento o santuário, menos frequentado por turistas, e mais atraído por devotos. $\mathrm{O}$ padrão religioso do catolicismo popular é exemplificado na análise da Capela da Medalha Milagrosa, em Paris. Esse centro religioso é apenas conhecido por devotos, isto é, peregrinos piedosos. Assim, o santuário atrai fiéis de países onde o catolicismo náo é predominante, como os peregrinos católicos da Indonésia muçulmana e Austrália protestante, demonstrando uma forte devoção aos cultos, oferendas e práticas religiosas católicas semelhantes em outros centros de peregrinação.

\section{Figura 2 - Alcance espacial da peregrinaçáo}

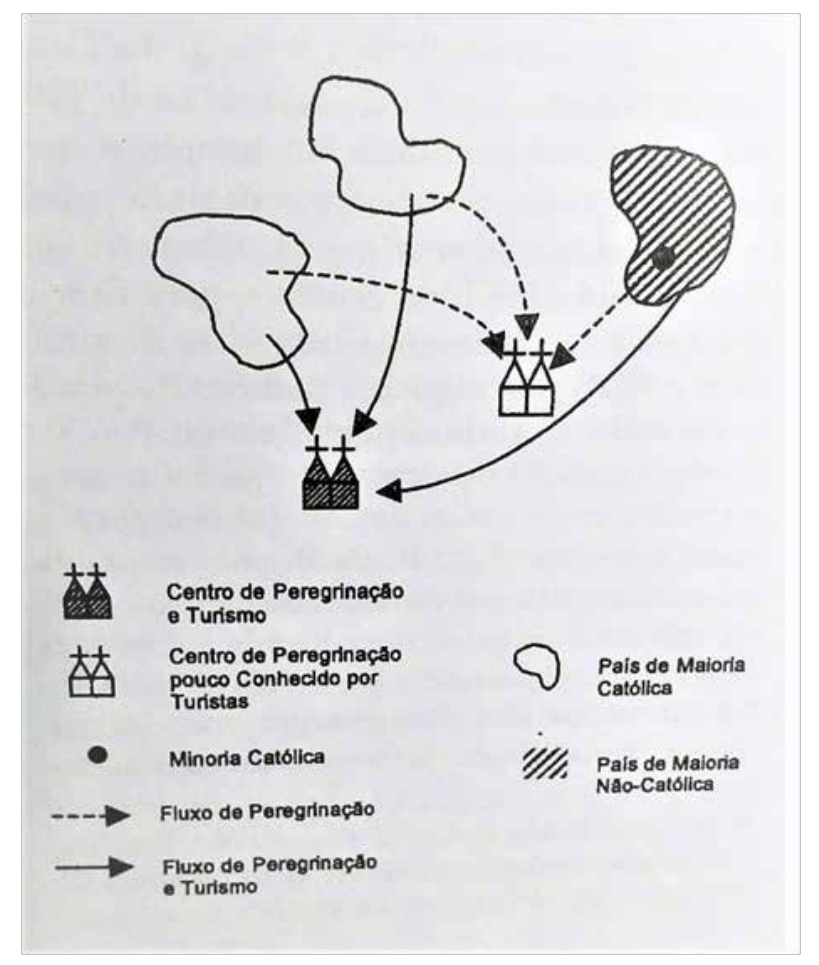

Fonte: Rosendahl (2009). 
No desejo de identificar o lugar sagrado em harmonia com a experiência da fé, em termos geográficos, privilegia-se o significado cultural do indivíduo ou do grupo social religioso no lugar em que ocorre a peregrinação. Esse lugar está impregnado de simbolismo e não foi meramente descoberto, fundado ou construído, mas reivindicado, possuído e operado por uma comunidade religiosa, conforme apontam Sopher $(1967,1984)$, Kong (1990), Park (1994), Rosendahl (1996, 2003a, 2003b, 2005) e outros estudiosos.

Existem, em Paris, espaços representativos de turismo com mais ou menos simbolismo em relação ao visitante, pois há o conhecimento do potencial de turistas à capital francesa. Paris, Cidade Luz desde o século XVII, atrai turistas por inúmeras atraçóes, quer no campo histórico e simbólico, no campo das artes, ou na paisagem do Rio Sena. Há exemplos: Torre Eiffel, Museu do Louvre, Catedral de Notre-Dame, Arco do Triunfo, Basílica de Sacré Coeur, Montmartre e seus jardins gramados e estátuas em pedestais. O turismo em escala mundial é reconhecido. Nos dados de hoje a cidade de Paris permanece como um centro mundial de turismo. De acordo com dados da Euromonitor International apresentados durante o evento da World Travel Market (WTM) no ano de 2017, sobre as cidades mais visitadas do mundo em 2016, a cidade de Paris apareceu na sétima colocação com mais de 14,4 milhôes de turistas (Euromonitor, 2017). Vale ressaltar que esse número apesar de expressivo apresenta leve queda devido aos últimos ataques terroristas ocorridos na Europa nos últimos anos.

Deseja-se numa breve reflexão reconhecer a vivência da dimensão simbólica espacial que ocorre no lugar pelo turista e pelo peregrino, na certeza de relembrar a maneira diferenciada da vivência no lugar por estes agentes espaciais. A importância da peregrinação que ocorre em Paris, cidade global, está inserida no vasto conjunto de motivaçôes dos turistas que a visitam. Acrescenta-se que a peregrinação à Rue du Bac evidência uma das inúmeras dimensôes da cidade, náo possuindo o mesmo peso, mas permitindo análise da dimensão religiosa, enriquecendo o conhecimento do lugar, ainda que esta peregrinação seja minimizada pela força de coesão do movimento turístico, devemos dizer - Paris é também uma hierópolis.

A literatura internacional indica os espaços representativos do turismo religioso que se compóem inicialmente do deslocamento de peregrinos e de turistas ao lugar sagrado. Escolhemos a visão: a) histórica; b) artística e; c) religiosa. A combinação dos três elementos não é o mais fundamental e sim a oportunidade que o homem tem de perceber no espaço sagrado a sua história, a sua arte e a sua fé.

Assim, é possível reconhecer espaços representativos da predominância do fator fé sobre os demais, ou a predominância da história do lugar como fator de convergência e a demonstração da arte: gótica, barroca, surrealista, popular e arte natural, como as florestas, campos e outros; representando e qualificando os lugares.

Este texto contribui com duas reflexóes: (a) a primeira aborda os conceitos teóricos desenvolvidos por Smith (1992); (b) a segunda a análise empírica realizada no ano de 1997, no lugar sagrado. Desta maneira, o objetivo é refletir, geograficamente, como a predominância de um dos três elementos: a história, a arte e a fé, sobre os demais, classificam a vivência do homem ou grupo social no espaço.

Os estudos empíricos realizados, no NEPEC e no Programa de Pós-graduação em Geografia / UERJ, como exemplo dos professores e pesquisadores: Sandy Regina Cadete 
Barbosa de Jesus (A organização socioespacial da cidade de Salvador sob a influência do sagrado: A festa de N. S. da Conceição da Praia); Victor Murilo Maia Fragoso (Grafia \& iconografia: traços identitários na Escola de Serviço do Senhor - Mosteiro de São Bento do Rio de Janeiro (1602-1802); José Arilson Xavier de Souza (Espaço de Peregrinação: ver o sentir o sagrado na Romaria de Nosso Senhor do Bonfim - TO), Jefferson Rodrigues de Oliveira ( $\mathrm{O}$ on e o off da fé na hipermodernidade: a religião e as novas interfaces do sagrado na era 2.0. O exemplo no Vale do Paraíba - SP); Karina Arroyo Crus Gomes de Meneses (Islam shiaa em perspectiva: novas consideraçóes sobre a construção de materialidades móveis e o conceito de território), em suas teses de doutorado indicam aos interpretarmos o comportamento do homem religioso no espaço sagrado que há bases teóricas de uma possível qualificação desse homem em suas manifestações religiosas.

A qualificação que adotamos refere-se à tipologia criada por Smith (1992) que envolvem experiências profundas com o sagrado. Reconhecemos cinco tipos de grupos sociais em diferentes espaços representativos. Os agentes modeladores nos santuários definidos são: a) Piedoso - peregrino (pious pilgrim); b) Peregrino - devoto (pilgrim over tourist); c) Peregrino - turista (pilgrim as much as tourist); d) Turista-peregrino (tourist more than pilgrim) e; e) Turista- secular (secular tourist).

Os cinco tipos contêm uma multiplicidade de motivaçóes espirituais que transcende o estudo geográfico e são próprios do lugar da vivência. São subjetivos. $\mathrm{O}$ vocábulo peregrino vem do latim peregrinus e significa itinerante, estrangeiro, aquele que anda por terras distantes. Vejamos, agora, dois tipos comportamentais selecionados que ilustram o exemplo empírico francês.

Acrescentamos que o lugar, a Capela da Medalha Milagrosa favorece ao exercício da fé e da identidade religiosa de grupo social que o frequenta. Os dois tipos usados nesta análise possuem harmonia com o ser e estar do homem seu roteiro geográfico de devoção e de turismo.

A distinção entre peregrinação e turismo ressalta que a viagem de peregrinação introduz dificuldades físicas ou sacrifícios que envolvem a separação da moradia, a liturgia no percurso da viagem e a chegada ao lugar sagrado. A viagem representa um ato religioso realizado por dever ou devoção e que assume um propósito espiritual. Já a viagem turística sugere um ato de lazer com a ausência de trabalho. E como tal, apresenta o desejo da fuga do cotidiano, a transição, indicada pelo percurso da viagem e a chegada ao lugar ou lugares.

O turista motivado pelo prazer, e não por obrigação, busca locais que despertam interesse de acordo com sua bagagem cultural e histórica de vida. $\mathrm{O}$ motivo da viagem é diferenciado para ambos que deixam seus lares, a vida cotidiana, pelo prazer de chegar a um lugar. $\mathrm{O}$ conceito de prazer, tomado num sentido genérico, relaciona-se às coisas que causam sensações agradáveis. O peregrino associa a saída à busca de comportamento espiritual, a busca pela transcendência. O elo dele com o divino.

Já o turista náo considera o prazer espiritual associado à transcendência. A motivação, para o grupo religioso, recai na esperança de obter graças e curas especiais. Nos grupos de turista, a motivação recai no desejo de escapar, temporariamente, das pressóes da sociedade em que vive. 
Em continuaçáo da análise do comportamento do homem, temos a segunda distinção entre peregrinação e turismo. Diz respeito à vivência e percepção do sagrado nos espaços representativos. O comportamento do peregrino difere do comportamento do turista nos lugares sagrados. O ritual religioso possui um conjunto de ritos e símbolos - em sua maioria náo decodificados pelo turista - cada aspecto, cada detalhe do rito possui um sentido que só é inteligível para o grupo religioso envolvido.

O peregrino é agente consumidor do sagrado e o turista um cliente usuário do lugar religioso. O peregrino como consumidor do sagrado justifica-se porque seu comportamento revela a prática de atividades religiosas como a de assistir missas e receber sacramentos.

Já o turista pode ter o desejo de vivência do espaço, mas sua prática comportamental está direcionada para o geral. Ele, o turista, desfruta da arquitetura do lugar, tem a necessidade de documentar, tirar fotos, filmar as formas espaciais religiosas. $\mathrm{O}$ consumo do sagrado não é meta fundamental da viagem turística.

O peregrino e o turista além de se diferenciarem quanto aos propósitos da visita, eles se diferenciam também quanto à espacialidade: tanto as que eles criam quanto as que foram criadas para eles.

\section{Paris: centro de peregrinaçáo e cultura popular}

Voltemos em nossa ideia de Paris - cidade de peregrinação, nas reflexóes das promessas e nos estudos dos ex-votos ${ }^{1}$. No corredor que une o portão principal da Congregaçáo Religiosas - 140, Rue du Bac até a porta da Capela da Medalha Milagrosa há no muro a vitrine de ex-votos - Figura 3.

\section{Figura 3 - Corredor de ex-votos}

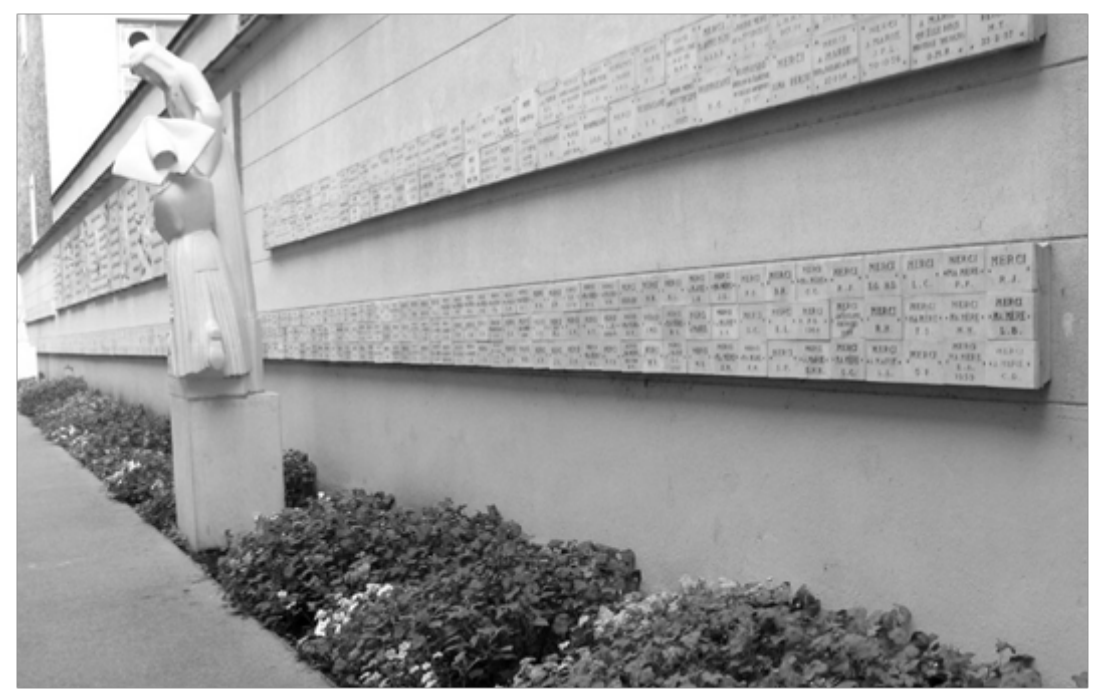

Fonte: Rosendahl, 2017.

1 VOTO, do latim VOTU, significa promessa. A expressão ex-voto é a abreviatura da expressão latina ex-voto suscipi, isto é, por uma promessa alcançada ou em consequência de uma promessa. 
A função devocional dos visitantes pode ser indicada pela existência das oferendas gravadas em mármore e colocadas ao longo do corredor de acesso a capela. Os estudos dos ex-votos como forma de arte ressaltam a (re)valorização de um material cultural e artístico. Criado na vivência da fé, da fantasia e do imaginário popular, revela a iconografia fortemente marcada pela influência da religiosidade católica. Cada peça fala de uma história de vida, de uma aflição superada, de uma realidade.

A entrega do objeto, pelo fiel, em recompensa ao favor divino recebido possui significado concreto designado pelo objeto. As peças expressam tanto o talento do artista como suas carências psico-socioeconômicas.

Inúmeras são as formas artísticas de se expressar. Algumas bastantes simples, outras bem complexas. $\mathrm{O}$ uso da madeira ou mármore ou outro material está relacionado à história de sucessivas geraçôes que transmitem sua cultura, seus costumes e tradições, crenças e valores que prevalecem no cotidiano dos tempos.

As revelaçóes entre o fiel e o divino são bastante semelhantes, tanto na modalidade da oferta como na escultura simbólica escolhida para o ritual (Rosendahl, 1999). A diversidade ocorre, então, pela religiosidade cultural do lugar, na revelação de seus mitos e valores. A cultura popular é, pois, componente necessário dessa diversidade, e os geógrafos não devem rejeitar tal evidência e sim interpretar os mecanismos que a criaram.

A partir do estudo de caso envolvendo a prática religiosa no catolicismo popular, de "fazer" e "pagar" promessas, trataremos dessa intimidade entre o crente e o divino. Constitui-se uma devoçấo tradicional e bastante comum no espaço sagrado e representa uma manifestação de fé que envolve o devoto e o santo numa relação direta, sem intermediários (Rosendahl, 1996, 2003b).

O peregrino faz o pedido - promessa - $\mathrm{e}$, uma vez alcançado, volta ao santuário para "pagar" sua dívida contratada com o santo. O devoto "paga" a promessa na hora, na forma e na maneira que deseja, não havendo nenhuma hierarquia religiosa para tal comportamento.

As notas aqui reveladas são resultado da pesquisa empírica realizada em 1997/1998, em Paris, na Capela da Medalha Milagrosa. A vitrine no corredor é um local invariavelmente visitado no roteiro devocional, não só pela curiosidade que desperta, como também pelo testemunho que representa, através de todos os objetos lá deixados pelos milhares de agradecidos pelas graças alcançadas. É a sala dos "ex-votos".

Cada "ex-voto" nos fala de uma história de vida, de uma dificuldade superada, de uma realidade dura e difícil. Cada objeto deixado possui um significado concreto designado pelo objeto. Esse símbolo é a maneira que o devoto encontrou para concretizar o seu imaginário, e que só poderá ser inteiramente entendido através do relato do crente que faz a promessa.

Os objetos colocados representam as "provas" ou "material" das conquistas no plano espiritual; seria como um "museu dos milagres". A pesquisa constou de análises dos "ex-votos" e da interpretaçáo das mensagens ouvidas.

Reunimos em três grandes grupos os pedidos encontrados. Eles se relacionam às carências básicas que classificamos como o Triângulo das Necessidades: saúde, trabalho e amor (Rosendahl, 1994). A pesquisa empírica demonstrou a "especialidade na saúde". 


\section{Consideraçóes Finais}

Este artigo deseja ressaltar a função espacial religiosa do Santuário da Medalha Milagrosa em Paris. A cidade francesa com suas peregrinaçóes na religiosidade católica, cumpre, assim, uma função social que se refere à ideia de Bourdieu (1987) "de livrar os crentes da angústia existencial, da contingência e do sentimento de abandono, ou mesmo da miséria biológica, da doença, do sofrimento ou da morte".

O movimento cultural, hoje, tenta associar peregrinação e turismo aos locais de forte valor simbólico religioso ou não. A cidade de Paris apresenta essa dualidade de funçôes: função de coesão devocional e função turística. Os lugares simbólicos possuem a presença harmônica de três elementos: história, arte e fé. As visões são singulares e estão na vivência sentida do homem de ser no espaço geográfico (Dardel, 2011).

Acrescenta-se que Paris é também uma cidade-santuário. Deve-se evidenciar que uma grande cidade é multidimensional em termos de suas atividades. Neste sentido a análise de cada dimensão funcional espacial possibilita o reconhecimento dessa complexidade. Permite, também, elaborar e enunciar as conexôes entre essas atividades.

A espacialidade é própria, específica em cada uma dessas atividades, mas que no conjunto transforma a cidade num complexo mosaico de formas espaciais irregulares e superpostas. A espacialidade e a temporalidade são próprias e específicas na cidade. A capela da Rue du Bac é um lugar de devoção e matriz de outras hierópolis da Medalha Milagrosa situadas em outros países.

\section{Referências}

ALLISON, K. "Pilgrimage and plebiscite: the political significance of the 1933". In BÜTTNER, M. (org.). Religion/ Umwelf-Forschung im Aufbruck. Bochum: Universitätsverlag Sh. N. Brokmeyer, 1989, v. 2.

BERGER, P. O Dossel Sagrado: elementos para uma teoria sociológica da Religião. Sáo Paulo: Paulinas, 1985.

BOURDIER, P. Gênese e estrutura do campo religioso. In: A economia das trocas simbólicas. 2. ed., São Paulo: Perspectiva, 1987.

CLAVAL, P. e SINGARAVELOU. Ethnogéographies. Paris, L'Harmattan, 1995.

CLAVAL, P. Religion et idéologie: perspectives géographiques. Paris: Press de l'Université Paris - Sorbonne, 2008.

DARDEL, E. O Homem e a Terra: natureza da realidade geográfica. São Paulo. Ed. Perspectivas. 1 $1^{a}$ edição [1952] 2011.

DURKHEIM, E. Les Formes Élémentaires de La Vie Religieuse. Paris: Presses Universitaires de France, 1968.

ELIADE, M. Imagens e Símbolos. Ensaio sobre o simbolismo mágico-religioso. Tradução de Sonia Cristina Tamer. São Paulo: Martins Fontes, 1991. 
EUROMONITOR, International. Site oficial. Disponível em: <http://www. euromonitor.com/>. Acesso em: 27 nov. 2017.

FILLE DE LA CHARITÉ, COMITÉ DE REDACTION. Une Lumierè sur la terre. Le message de Marie à Sainte Catherine Labouré. França: Editions du Signe, s/data.

ISAAC, E. Religion, landascape and space, Landscape. California, v.9, n.4, p. 14-18, 1959-1960.

KONG, L. Geography and religion: trends and prospects. Progress in Human Geography. Londres, v. 14 (3), p. 355-371, 1990.

MARTINS, M. Medalha Milagrosa. MTB 31127. Sáo Paulo: AIS Brasil, 2004.

NORA, P. Between Memory and History: les lieux de mémoire. Representations. Berkeley: University of California, v. 26 (1), p. 1-25, 1989.

NORTON, W. Cultural geography: themes, concepts, analyses. Oxford: Oxford University Press, 2000.

OTTO, R. O Sagrado. Lisboa: Ediçôes 70, 1992.

PARK, C. Sacred Worlds: an introduction to geography and religion. Londres: Routledge, 1994.

ROSENDAHL, Z. Porto das Caixas: espaço sagrado da Baixada Fluminense. 1994. Tese. (Doutorado em Geografia) - Departamento de Geografia, Universidade de São Paulo, São Paulo, 1994.

ROSENDAHL, Z. Espaço e Religião: Uma Abordagem Geográfica. Rio de Janeiro: EdUERJ, 1996. $92 \mathrm{p}$.

ROSENDAHL, Z. O sagrado e o profano. In: ROSENDAHL, Z.; CORREAA, R. L. (Orgs.) Manifestaçóes da cultura no espaço. Rio de Janeiro: EdUERJ, 1999. p. 9-39.

ROSENDAHL, Z. Espaço, Cultura e Religião: Dimensões de Análise. In: CORREAA, R.L.; ROSENDAHL, Z. (Orgs.). Introdução à Geografia Cultural. Rio de Janeiro: Bertrand Brasil, 2003a. p. 187-226.

ROSENDAHL, Z. Construindo a Geografia da Religiáo no Brasil. Espaço e Cultura, Rio de Janeiro, n. 15, p. 61-67, jan./jun. 2003b.

ROSENDAHL, Z. Território e Territorialidade: Uma perspectiva Geográfica para o Estudo da Religiáo. In: ROSENDAHL, Z; CORREA, R. L. (Orgs.). Geografia: Temas sobre Cultura e Espaço. Rio de Janeiro: EdUERJ, 2005, p. 191-226.

ROSENDAHL, Z. Hierópolis: o sagrado e o urbano. 2. ed. Rio de Janeiro: EdUERJ, 2009. 118 p.

ROSENDAHL, Z. Uma Procissão na Geografia. Rio de Janeiro: EdUERJ, 2018. 
SACK, R. D. Human territoriality: its theory and history. Cambridge: Cambridge University Press, 1986.

SANTOS, A. A. A verdadeira história da Medalha Milagrosa. São Paulo: Artpress, 1998.

SMITH, V. L. Introduction: The quest in guest. Annals of Tourism Research. USA, v. 19, Issue 1, p. 1-17, 1992.

SOPHER, D. E. Geography of religions. Londres: Englewood Cliffs/Prentice Hall, 1967.

SOPHER, D. E. Geography and religions. Progress in Human Geography, Londres, n. 5 (5), p. 511-24, 1984.

WEBER, M. Economía y Sociedad. México e Buenos Aires: Fondo de Cultura Económica, 1964.

Recebido: 19 de julho de 2019.

Aprovado: 2 de dezembro de 2019. 